\title{
Effect of submucosa of small intestine on intestinal anastomosis in goats.
}

\author{
M.J.Eesa N.H.Alfalahi M.S.Dauod \\ Vet. Med. Coll. / Univ.of Baghdad
}

\begin{abstract}
The aim of this study was to investigate the effect of small intestinal submucosa (SIS) on healing of intestinal anastomosis in goats. Twelve local breed bucks were used. Animals were divided into two equal groups, in the first group the anastomotic site after resection of 4 $\mathrm{cm}$ from the jejunum was sutured by horizontal mattress pattern, considered as a control group. In second group, after anastomose was covered by small intestinal submucosa, prepared previously and fixed with the anastomotic site by multiple stitches of simple interrupted suture. Experimental animals were observed clinically, after 15 and 30 days postoperation, sample of anastomosis site were examined grossly and histopathologically. Grossly in control group moderate to severe adhesion of anastomotic site with the surrounding tissue were found as compared with the moderate adhesion in the treated group. The bursting pressure, in control group was $(150 \pm 2.9)$ and $(178.3 \pm 4.5) \mathrm{mmHg}$, while in treated group was $(185 \pm 2.9)$ and $(208.3 \pm 4.5) \mathrm{mmHg}$ at a period of 15 and 30 days post operation respectively. The degree of stenosis in control group was $(59 \pm 1.5)$ and $(49 \pm 2.2)$, while in treated group was $(76 \pm 5.6)$ and $(36.3 \pm 0.6)$ at a period of 15 and 30 days post operation respectively. The histopathological findings revealed that the healing process was more prominent in treated group than in control group. In conclusion of this study investigated that submucosa of small intestine enhances healing of intestinal anastomosis.
\end{abstract}

\section{Introduction}

Diseases of the small intestine requiring surgical intervention remain a significant problems and the post operative complications most commonly reported which contribute to the poor survival rate with small intestinal disease include intraabdominal adhesions, anastomotic leakage , ileus and peritonitis (1).Intra-abdominal adhesions are a significant cause of post operative intestinal obstruction undergoing abdominal surgery and intestinal resection and anastomosis for small intestinal disease. The adhesions becomes a clinical problem when they compress or anatomically distort the intestine, this may lead to intestinal constriction, incarceration or volvulus, predisposing the patient to intestinal obstruction and signs of abdominal pain .So a numerous clinical trials and laboratory investigations have been devoted to determining methods of minimizing the formation of post operative intra abdominal adhesions ,broad spectrum antibiotics non- steroidal antiinflammatory agent ,heparin , intra- peritoneal administration of high molecular weight solutions ,temporary protective barrier agents, omentectomy and post operative peritoneal lavage have all been advocated to minimize adhesion formation (2). Because of difficulty in preventing anastomotic dehiscence, variety of products has been tested to provide protection to the anastomosis site (3). Recently porcine - derived small intestinal submucoa (SIS) has been introduced as a reinforcement of soft tissue (4), which is considered as a cellular collagen - based matrix primarily composed of febrile collagens (5) that enhance healing while stimulating a minimal immune response (6). Studies have shown that SIS serves as a bio- scaffold for healing of a wide variety of tissues and organs such as urinary bladder, blood vessels, and tendons (7). In our present study it evaluated the effectiveness of small intestinal sub mucosa on healing of jejunum anastomotic site in bucks. 


\section{Materials and Methods}

This study was done on twelve bucks of local breed (20- $30 \mathrm{~kg}, 1.5-3$ years of age), they divided randomly into two equal groups, control group and treated group. The small intestine was harvested from the sheep and mechanically separating the submucosa from the outer muscular layers and the internal mucosal layer, then rinsed in highly purified water, treated with an aqueous solution of $0.1 \%$ per acetic acid for $2 \mathrm{hr}$ to ensure viral safety and then rinsed in sequential exchanges of water and buffers to yield a neutral ph. It was then freeze-dried to stabilize the proteins within it and is later sterilized using $70 \%$ ethanol alcohol for $(18 \mathrm{hr})$, then rinsed with sterilized distilled water for (10 minute) then lyophilized the specimens until it's used(8 and 9), (Fig.1).

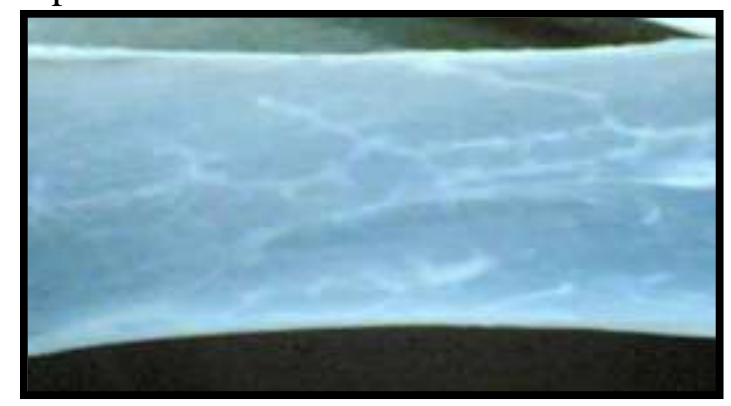

(Fig.1): Small intestinal sub-mucosa after preparation.

Surgical operation was done after the preoperative preparation of the animal by withheld $24 \mathrm{hr}$ from eating and $12 \mathrm{hr}$ from drinking, with the intramuscular injection of pen - strept in a dose 10,000 and 20 $\mathrm{mg} / \mathrm{kg} \quad$.B.W.respectively before the operation. Then surgical preparation of the right flank, and under sedated the animal by Xylazine $0.01 \mathrm{mg} / \mathrm{kg}$. B.W. intramuscular (10) and the site of operation anaesthetized by local infiltration by Xylocaine $2 \%$. Laparotomy was done, then $4 \mathrm{~cm}$ of jejunum was resected and anastomosis of two ends by polygalactine 910 (No. 3-0) with interrupted horizontal mattress suture in control group. While in treated group, same manner but the anastomotic site was covered by small intestinal submucosa and fixed with the anastomotic site by multiple stitches of simple interrupted suture pattern. Then routinely closed abdominal wall. The animals were observed clinically. The anastmotic site was tested macroscopically with measuring of stenosis degree by filling of the resected segment of anastomotic site by saturated barium sulfate $(25 \%)$ and radiographed under exposure(KV 40 and 3 $\mathrm{mAs}$ ). Then measuring the anastmotic site according to the formula(11): Stenosis degree $=100(1-2 A / B+C) \cdot A=$ Diameter of anastomosis site, $\mathrm{B}$ and $\mathrm{C}=$ Diameter of intestine $2 \mathrm{~cm}$ proximally and distally from the anastomosis site. The bursting pressure was measured in $\mathrm{mmHg}$ by using pressure meter through pushing air into resected segment sunken in water filled to detect air bubble leakage from anastomotic site or from other site of segment. Histopatholgical study was done for the anastomotic site at a period 15 and 30 days post operation and sections were stained with hematoxylin and eosin to study the process of healing in two groups. The statistical analysis used to detect the degree of stenosis and bursting pressure in between two groups of experimental animals.

\section{Results}

Clinically, the experimental animals showed that, the defecation, urination, and appetite return to normal after 4-6 days postoperation.Gross examination of anastomosis site revealed that, there were no signs of leakage from the anastomotic site in treated group, no abscess ,no signs of peritonitis and there was mild adhesion between anastomotic site and adjacent organs(Fig.2). There were moderate to severe adhesions between the anastomotic site and omentum, mesentery and loops of intestine in control group(Fig.3). 


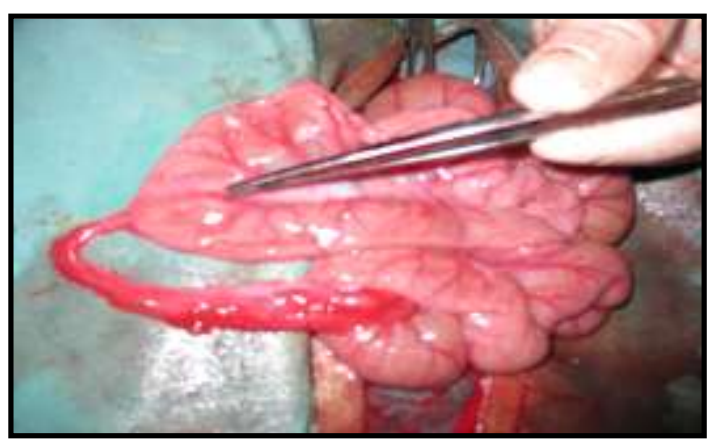

(Fig.2): Adhesion like cord between anastomotic site and loop of intestine in treated group.

The degree of stenosis was revealed that, no significant differences between the control and treated group at the level of $\mathrm{p}<$ 0.05 ( table, 1) and radiograph of intestine of two groups at 15 and 30 days post operation (Fig.4, 5, 6 and 7). The results

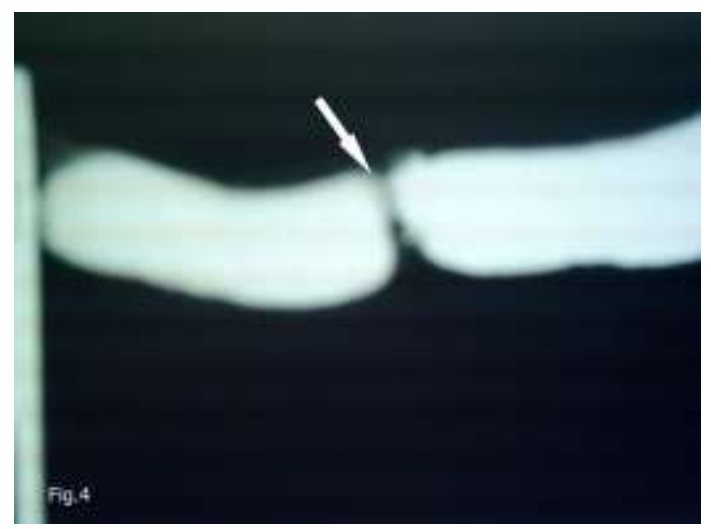

Fig.4: Radiograph of the anastomostic site at 15 days post operation in control group.

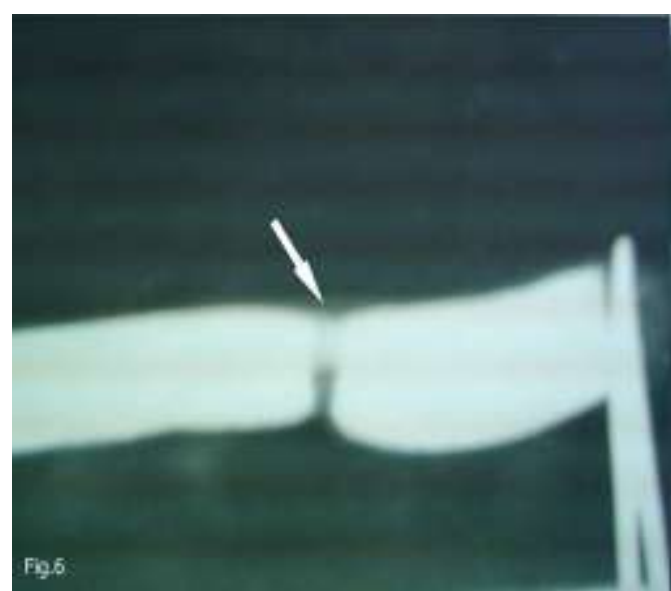

Fig.6:Radiograph of the anastomostic site at 15 days post operation in treated group.

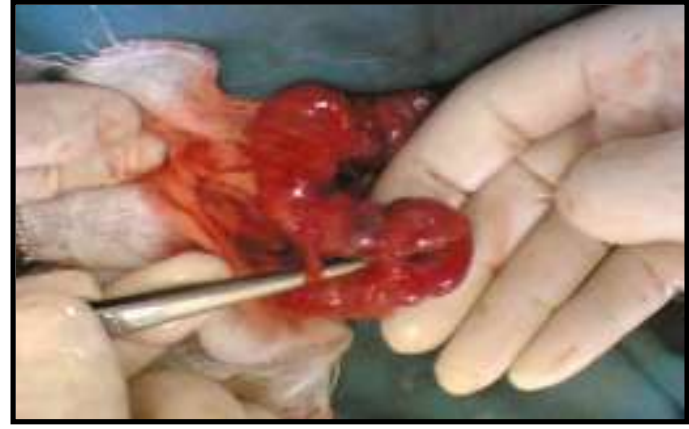

(Fig.3): Adhesion between anastomotic site and intestinal loop in control group.

of bursting pressure should no significant differences between two groups at 15 days post operation, but there were a significant differences between the two groups at 30 days post operation at the level of $p<0.05$ ( table,2).

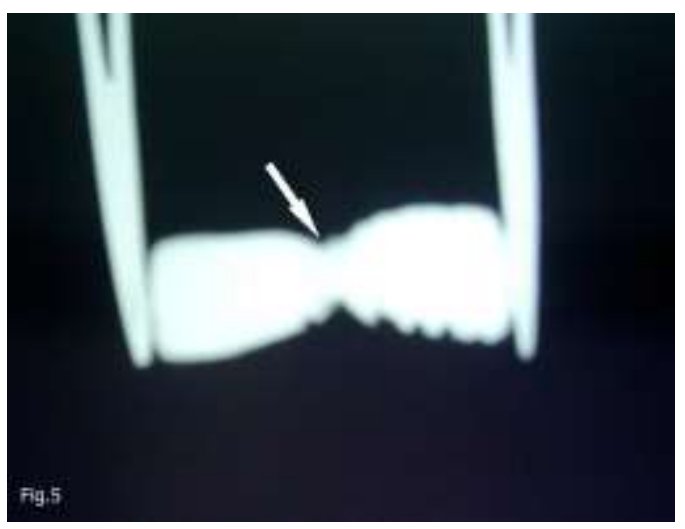

Fig.5: Radiograph of the anastomostic site at 30 days post operation in control group.

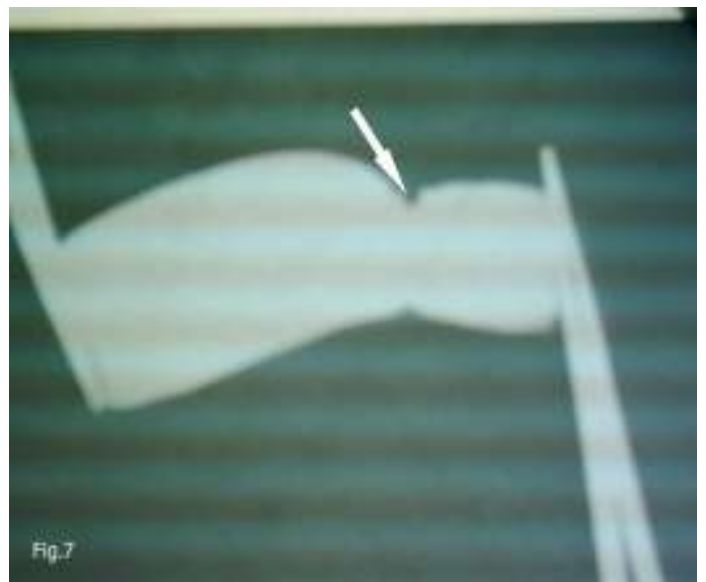

Fig.7: Radiograph of the anastomostic site at 30 days post operation in treated group. 
Table (1): Mean of stenosis degree \pm standard error in two groups in days (15 and 30) $n=6$.

\begin{tabular}{|l|l|l|}
\hline \multirow{2}{*}{ Groups } & \multicolumn{2}{|c|}{ times } \\
\cline { 2 - 3 } Control group & $59 \pm 1.5$ & $49 \pm 2.2$ \\
\hline Treated group & $76 \pm 5.6$ & $36.3 \pm 0.6$ \\
\hline
\end{tabular}

Table (2): Mean of bursting pressure \pm standard error in two groups in days (15 and 30) .

\begin{tabular}{|l|l|l|}
\hline \multirow{2}{*}{ Groups } & \multicolumn{2}{|c|}{ Times } \\
\cline { 2 - 3 } Control group & 15 day & 30 day \\
\hline & $150 \pm 2.9 \mathrm{mmHg}$ & $178.3 \pm 4.5 \mathrm{mmHg}$ \\
\hline & & \\
Treated group & $185 \pm 2.9 \mathrm{mmHg}$ & $208.3 \pm 4.5 \mathrm{mmHg}$ \\
\hline
\end{tabular}

Hitopathological findings, in control group days 15 post operation, showed the presence of the epithelial layer lies on granulation tissue which infiltrated by mononuclear inflammatory cells with presence of congested blood vessels (Fig.8), also there were fibrin net which infiltrated by inflammatory cells at the site of anastomosis (Fig.9). After (30) days postoperatively there was infiltration of inflammatory cells with the presence of granulation tissue which connected the muscular layer of mucosa (Fig.10), also its

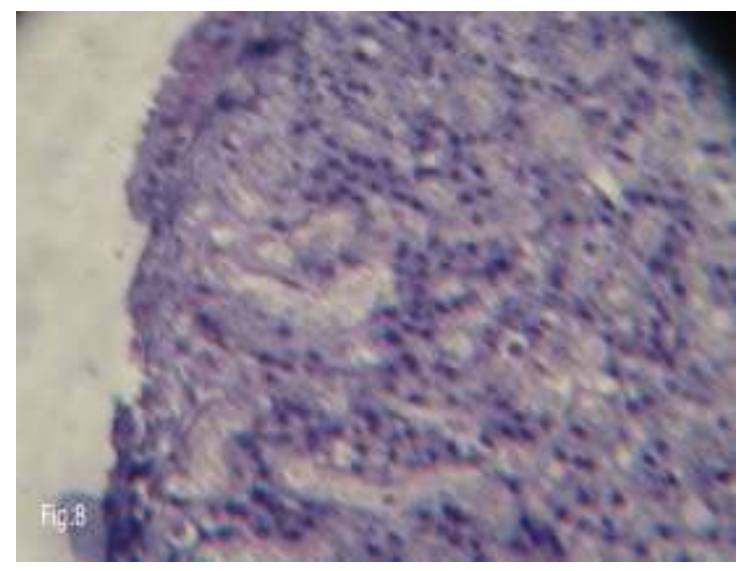

Fig.8: Presence of the epithelial Layer lies on granulation tissue Which infiltrated by mononuclear inflammatory cells after 15 days in control group.(H\&E 40X) observed from 2-3 of columnar epithelial layers lies over the granulation tissue which infiltrated by inflammatory cells (Fig.11 and 12). Treated group15 days post operation the anastomotic site showed an infiltration of mononuclear inflammatory cells with the presence of 2-3 mucosal columnar epithelial layers (Fig.13), with the presence of neo-vascularization. After (30) days post operation showed completely healing of the small intestinal mucosa, including villus like configuration (Fig.14 and 15).

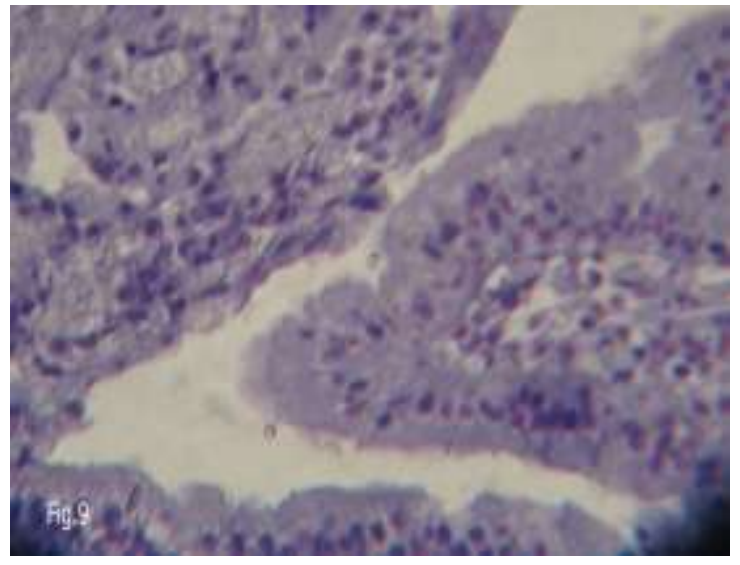

Fig, 9: There was a fibrin net work which infiltrated by inflammatory cells at the site of anastomosis after 15 days in control group. (H\&E 40X) 


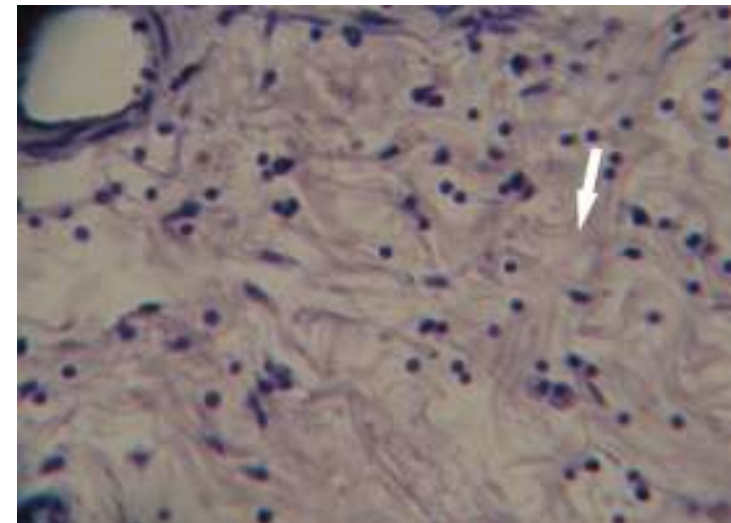

Fig (10): There was infiltration of inflammatory cells with the presence of granulation tissue (arrow) which connected the muscular layer of mucosa after 30 days in control group. (H\&E 40X)

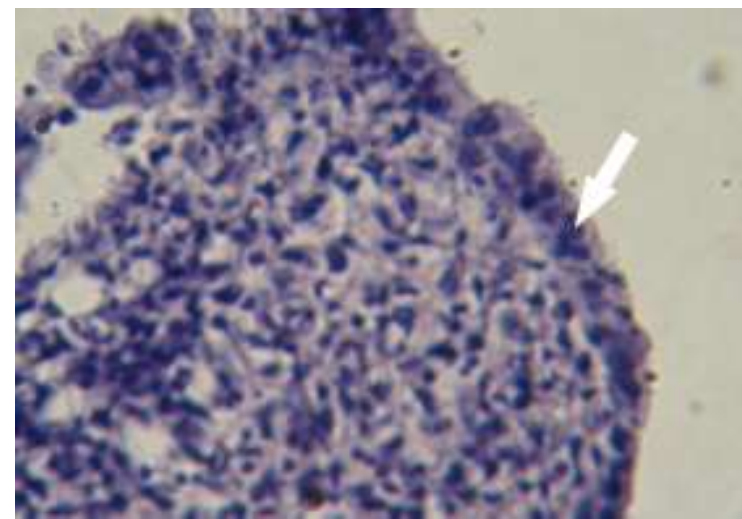

Fig (12): Infiltration of mononuclear inflammatory cells with the presence of 2-3 mucosal columnar epithelial layers at the site of anastomosis(arrow) after 30 days in control group.

(H\&E 40X)

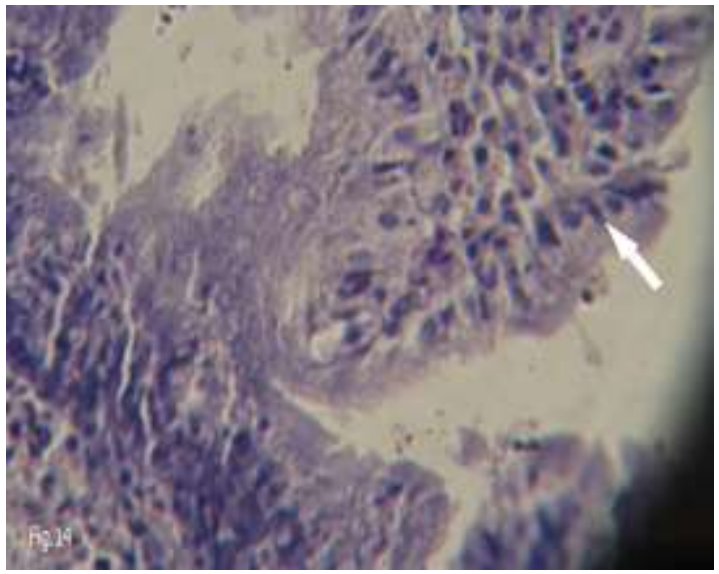

Fig (14): The anastomotic site revealed villus like configuration lined by columnar cells infiltrated by mononuclear inflammatory cells (arrow) after 30 days in treated group. (H\&E 40X)

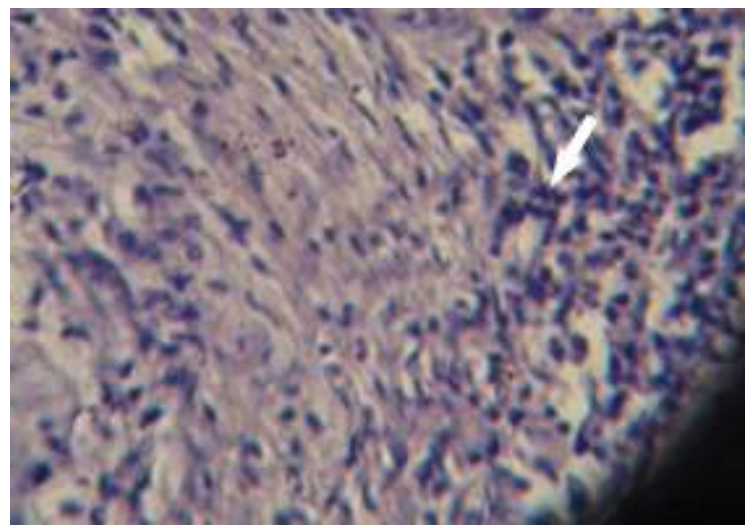

Fig (11): There was the granulation tissue which infiltrated by inflammatory cells (arrow) after 30 days in control group (H\&E X40).

(H\&E 40X)

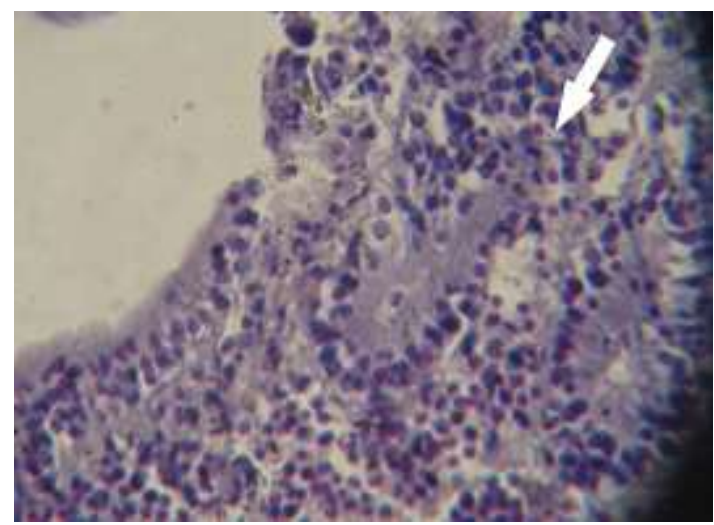

Fig (13): Infiltration of mononuclear inflammatory cells (arrow) with the presence of 2-3 mucosal columnar epithelial layers after 15 days in treated group. (H\&E 40X)

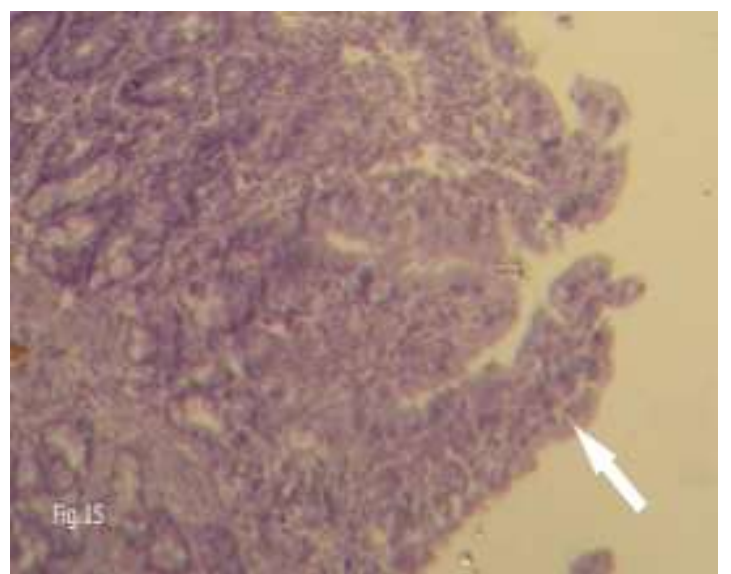

Fig (15): The anastomotic site completely regenerated to the small intestinal mucosa, including villus like on figuration (arrow) after 30 days in treated group. (H\&E 40X) 


\section{Discussion}

Biomaterials play a critical role in engineering of new functional tissue for the replacement of lost or mal-functioning tissue, they provide a temporary scaffolding to guide new tissue growth and organization, in this study the clinical signs has been shown non-immunogenic with no signs of rejection to SIS this from a viewpoint of some investigators refer to scaffold degradation in early time and totally replaced by organized collagen tissue by 2 weeks post operation this phenomena coincided with (12). The macroscopic findings for the control group indicated that the incidence of moderate to severe adhesion around the anastomotic site, some investigators related this adhesion to the eversion of mucosa which lead to its exposure to bacteria or may be from the pressure of suture materials which lead to increase inflammatory phase with high incidence of edema and less oxygenation lead to adhesion formation this coincided with(13). While in the treated group the small intestinal submucosa decrease the incidence of adhesions may be due to, it cover the anastomotic site and it appeared an effective biodegradable scaffold, facilitating regeneration of intestinal tissue. This fact was described by other workers (14). The bursting pressure has been shown significant differences at

\section{References}

1) Randy, B.E.; Eric, $M$ and Lisa, N.; et.al. (2000).Evaluation noval method of jejunal anastomosis in horses using a hyaluronate membrane. Proceeding of the annual conversion of the AADB.46: 107.

2) Mueller POE.; Hay WP and Harmon BG, et al. (2000). Evaluation of a Bioresorbable hyaluronatecarboxymethylcellulose membrane for prevention of experimentally induced abdominal adhesions in horses. Vet Surg; 29:48-53.

3) Caga.T and Gurer.f. (1993). Polytetrafluoroethylene patch grafting for closure of stomach defects in the rat.Br.J.Surg; 80:10131014. the level of $p<0.05$ between the two groups in 30 day only. This may be due to the sub mucosa of small intestine enhance healing, which lead to increase strength of the intestinal wall and ultimately, increases the bursting pressure. This result was agreed with other authors (14). The results of histopathological findings revealed that the angiogenesis, cell migration, differentiation and the deposition of extra-cellular matrix have been associated with the regeneration process in treated group this agreed with the results of some investigators (15,16 and17). They explain that, the cellular and tissue remodeling develops in response to the small intestinal submucosa that it consist mainly of extra cellular matrix, that has been shown to be rich in components that support angiogenesis, such as fibronectin, glycosaminoglycans including heparin, several collagens, and angiogenic factors, such as basic fibroblast growth factor (FGF-2), and vascular endothelial cell growth factor (VEGF). The host remodeling occurred primarily from mononuclear and fibroblast cellular invasion also the columnar epithelium completely covered the anastomotic site. In conclusion of this study, observed that SIS is an effective bio-degradable scaffold, facilitating healing of intestinal tissue.

4) Clark,K.M.;Lantz,G.C.;Salisbury,S.K.;B adylack,S.F.;Hiles,M.C and voytik,S.L.(1996). Intestinal submucosa and polyprolenemesh for abdominal wall repair in dogs.J.Surg.Res.60:107-114.

5) Oytik-Harbin SL,; Brightman AO,; Waisner BZ,; Robinson JP, and Lamar CH (1998). Small intestinal submucosa: A tissue-derived extracellular matrix that promotes tissue-specific growth and differentiation of cells in vitro. Tissue Eng. 4:157-174.

6) Allman AJ, McPherson TB, Badylak SF, Merill LC, Kallakury B, Sheehan C, Raeder RH and, Metzger DW (2001). Xenographic extracellular 
matrix grafts elicit a $\mathrm{TH}$-2-restricted immune response. Transplant. 71:1631-1640.

7) Sebastian G.; Marcia R. Gottfried.; D. Curtis Lawson. Mary B. Harris, R.V.T., Christopher R. Mantyh. and Theodore N. Pappas. (2003). Evaluation of Porcine-Derived Small Intestinal Submucosa as a Biodegradable Graft for Gastrointestinal Healing. J. of Gastrointestinal Surg.7 (1):96-101.

8) Badylak, S.F. (1993). Small intestinal sub mucosa (SIS): A biomaterial conductive to smart tissue remodeling. In: Bell E (Ed). Tissue Engineering:Current Perspectives. Cambridge, A: Burkhauser Publishers; 179-189.

9) Darryl, A.D. (2003). Baseline creep characterization of collagen fiber scaffolds. $\mathrm{J}$ of Young Investigators .Issue 1, V (8).

10) Booth, N.H. and McDonald E.L. (1988). Veterinary pharmacology and therapeutics. $6^{\text {th }}$ ed., Lowa stste University Press. P: 262-348.

11) McAdams, A.J.; Meikle, G.and Medina, R. (1969). An experimental comparison of inversion and evertion colonic anastomosis. Diseases of colon and rectum. 1211-1216.
12) Chcy, E.Y.and Kropp, H.P. (2000). Urologic tissue engineering with small intestinal submucosa: potential clinical applications. World.J.Urol. 18:26-30.

13) Samiullah, Mohammad Israr, Naik Zada. (2003). Comparison of single layer interrupted intestinal anastomosis with double layer intestinal anastomosis. Original article. 17(2):263-266.

14) Savas, D.; Turan, k.; Ilyas, O.; mchmet, N.E. and Sclcuk, Y. (2003). Using porcine small intestinal submucosa in intestinal regeneration. Pediatr.Surg.Int.19: 588-592.

15) Hdde,J. P,; Badylak,S.F.; Brightman, A.O and Voytik-Harbin,SL.( 1996). Glycosaminoglycan content of small intestinal submucosa: a bioscaffold for tissue replacement. Tissue Eng.2:209-217.

16) McPherson, T.B and Badylak, S.F. (1998).Charactirization of fibronectin derived from porcine small intestinal submucosa.Tissue Eng.4:75-83.

17) Voytik-Harbin,SL. Brightman, A.O.; Kraine.M.R.; Waisner,B and Badylak, S.F.(1997).Identification of extractable growth factors from small intestinal submucosa.J Cell Biol.67:478-491.

$$
\begin{aligned}
& \text { تأثثر غشاء تحت المخاطية للمعي الدقيق في تفمم الامعاء في المعز. }
\end{aligned}
$$

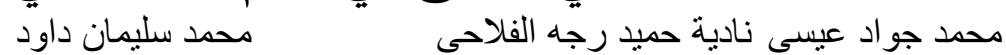

$$
\begin{aligned}
& \text { كلية الطب البيطرى/ جمامعة بغداد }
\end{aligned}
$$

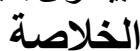

الهدف من هذه الدر اسة لملاحظة تاثير غشاء تحت المخاطيـة للمعي الدقيق في التئسام منطقة تفمم الامعـاء في

المعز.اجريت هذه الدر اسة على اثنى عشر من ذكور المعز المحلية وقسمت اللى مجمو عتين متسـاوية ، المجمو عـة الاولى فئ

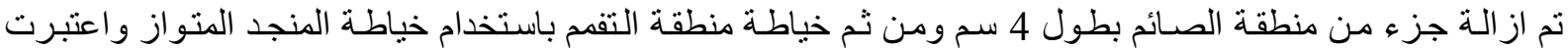

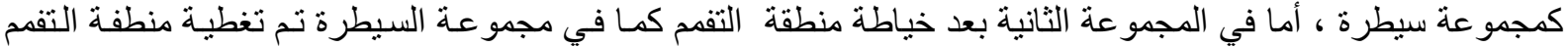

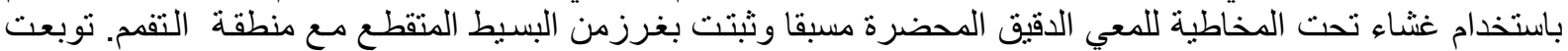

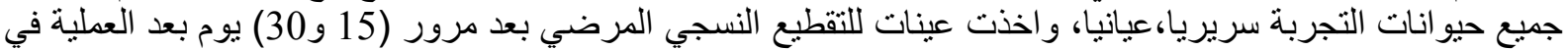

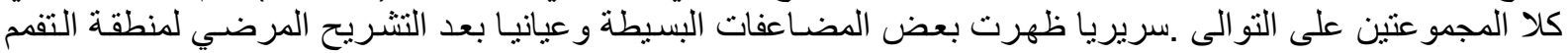

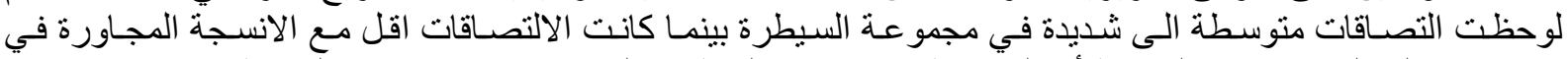

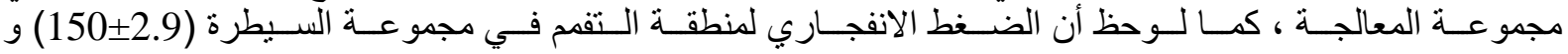

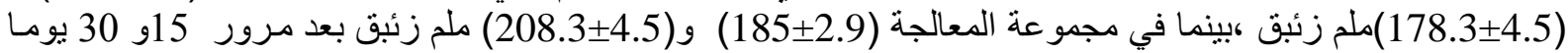

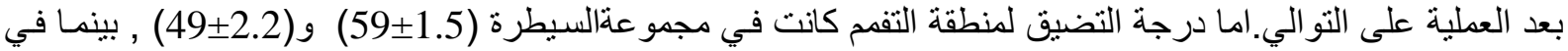

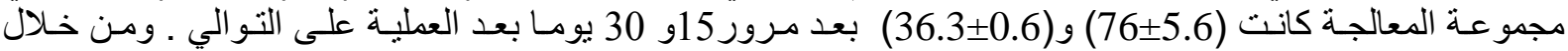
الفحص النسجي المرضي لوحظ ان الالتئام في مجموعة المعالجة كان افضل من مجموعة السيطرة ، نستنتج من الدراس اسـة

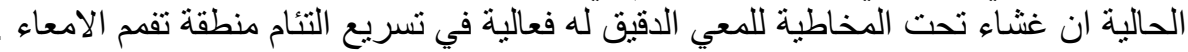

